\title{
"PENGARUH TEMPERATUR TUANG DENGAN JENIS MATERIAL PADUAN AI RONGSOK (KAMPAS REM PANCI) TERHADAP POROSITAS, KEKERASAN DAN STRUKTUR MIKRO HASIL PENGECORAN EVAPORATIVE”
}

Syaiful Rahman, Rudi Siswanto

Program Studi Teknik Mesin,

Fakultas Teknik Universitas Lambung Mangkurat

JL. Akhmad Yani Km.36 Banjarbaru, Kalimantan Selatan,70714

Telp. 0511-4772646, Fax 0511-4772646

E-mail : Rahmanthh18@gmail.com

\begin{abstract}
Abstrak. Daur ulang aluminium bekas merupakan salah satu alternatif untuk menekan limbah (rongsok) dari aluminium. Daur ulang adalah salah satu cara pengolahan sampah yang dilakukan mulai dari pemilihan, pengumpulan lalu dilakukan proses pegecoran untuk membuat produk yang baru yang lebih bernilai ekonomis. Temperatur tuang salah satu variabel yang dapat mempengaruhi hasil coran dimana jika temperatur tuang rendah maka akan terjadi pembekuan cepat sebelum cetakan terisi penuh, dan jika temperatur tuang terlalu tinggi dapat terjadi penyusutan dan nilai porositas dapat meningkat, dalam penelitian ini menggunakan temperatur tuang $650^{\circ} \mathrm{C}, 700^{\circ} \mathrm{C}, 750^{\circ} \mathrm{C}$ dan $800^{\circ} \mathrm{C}$. Tujuan dari penelitian ini adalah untuk mengetahui pengaruh temperatur tuang dengan jenis material paduan $\mathrm{Al}$ rongsok dari sepatu kampas rem dan panci terhadap porositas, kekerasan dan struktur mikro hasil pengecoran evaporative. Metode pengecoran evaporative menggunakan pola styrofoam yang ditimbun didalam pasir cetak, logam yang dicor akan membentuk seperti pada pola styrofoam. Hasil dari pengujian temperatur tuang berpengaruh terhadap porositas, kekerasan dan struktur mikro.
\end{abstract}

Kata kunci: Evaporative, temperatur tuang, Aluminium, sepatu kampas rem, panci.

Recycling is a way of processing used materials that is started with selection, collection, then the process of foundry to create a new product that is more valuable economical. The objective of this research is to know the effect of casting temperature with the kind of guide material AI alloy junk from brake shoe and pan on porosity, hardness, microstructure (the evaporative foundry result). The recycling of used aluminum is an alternative to reduce the waste material from aluminum. Casting temperature is an variable that can effect the result of foundry where if the casting temperature is low, then there will be a quick freeze before the mold is completely filled. And if the casting temperature is too high, then shrinkage can occur and the porosity value may increase. This research used four casting temperature variations, namely: $650^{\circ} \mathrm{C}, 700^{\circ} \mathrm{C}, 750^{\circ} \mathrm{C}$, and $800^{\circ} \mathrm{C}$. The evaporative foundry method uses styrofoam pattern that is piled up into sand mold. The metal that is casted will form like styrofoam pattern. The result of casting temperature testing can effect on porosity, hardness, and microstructure.

Keywords: evaporative, Casting temperature, aluminium, brake shoe, fan 


\section{PENDAHULUAN}

Aluminium merupakan salah satu unsur kimia. Dengan lambang $A l$, dan nomor atomnya 13. Aluminium juga merupakan logam paling berlimpah. Aluminium tidak termasuk jenis logam berat, Aluminium ialah unsur yang berjumlah sekitar $8 \%$ dari permukaan bumi dan paling berlimpah ketiga setelah oksigen dan silikon.

Aluminium digunakan dalam banyak hal, dan dapat digunakan dalam kabel bertegangan tinggi. Secara luas juga digunakan dalam bingkai jendela dan badan pesawat terbang, pada peralatan rumah sebagai panci, botol minuman ringan, tutup botol susu dan sebagainya, dan komponen komponen mesin. Karena aluminium banyak digunakan dalam kehidupan manusia maka sampah rongsokan dari limbah aluminium juga banyak tidak termanfaatkan dengan baik. Salah satu kegiatan daur ulang yang dapat dilakukan pada aluminium adalah melalui proses peleburan. Peleburan logam ialah suatu proses pencairkan logam pada temperatur tertentu dengan menggunakan energi panas yang dihasilkan oleh open ataupun tungku. Tungku adalah sebuah peralatan yang digunakan untuk melelehkan logam.

Temperatur tuang adalah salah satu variabel yang dapat mempengaruhi hasil coran, sebab jika temperatur tuang terlalu rendah akibatnya rongga cetakan akan tidak terisi penuh logam cair akan membeku sebelum memenuhi cetakan, dan jika temperatur tuang terlalu tinggi hal ini akan mengakibatkan porositas yang tinggi dan hasil coran mengalami penyusutan atau kehilangan keakurasian dimensi

Pengecoran (casting) merupakan suatu proses penuangan material cair seperti logam atau plastik ke dalam cetakan, kemudian dibiarkan membeku di dalam cetakan tersebut, dan kemudian dikeluarkan atau di pecah-pecah untuk dijadikan suatu komponen. Pengecoran biasanya digunakan untuk pembuat bagian mesin dengan bentuk yang kompleks (Surdia dkk, 2000).

Pengecoran evaporative merupakan salah satu metode dalam pengecoran logam, yang mana pola dan sistem saluran menjadi satu-kesatuan yang terbuat dari bahan styrofoam. Pola pengecoran evaporative merupakan pola yang hanya sekali pakai, dimana pola dari bahan styrofoam akan menguap jika terkena panas logam cair. Metode ini dilakukan dengan cara pola dan sistem saluran (styrofoam) di tanam dalam pasir cetak dengan posisi sistem saluran tuang mucul di permukaan pasir cetak, sebagai saluran masuk logam cair, selanjutnya pada proses penuangan logam cair dituangkan ke saluran yang sudah disiapkan, logam cair masuk dan secara bersamaan pola akan terbakar terbakar (menguap) sampai logam cair memenuhi cetakan pasir.

Temperatur tuang meruapakan salah satu unsur yang penting dan harus diperhatikan dalam memproduksi produk pengecoran dengan kualitas tinggi, sebab faktor ini sangat berpengaruh terhadap kualitas coran yang meliputi mikro struktur dan sifat mekanisnya sehingga didapatkan hasil coran yang mempunyai sifat fisik yang diinginkan. Diagram fasa temperatur tuang dapat di lihat pada Gambar 1.

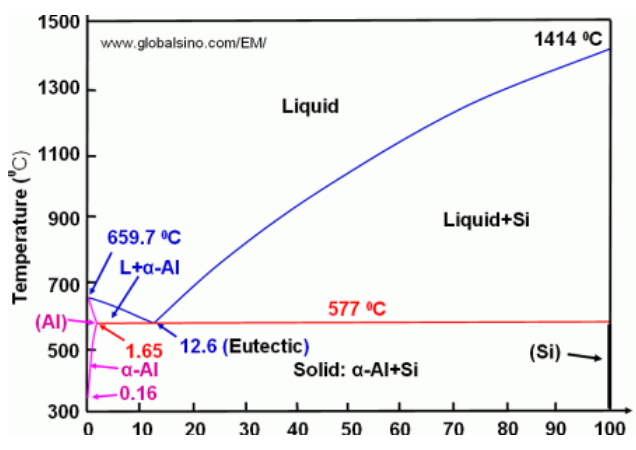

Gambar 1. Diagram fasa Al-Si 


\section{Pengujian}

a. porositas

Porositas atau suatu cacat (void) meruapakan gas yang terjebak pada saat pembekuan pada produk cor yang dapat menurunkan kualitas benda tuang. Salah satu penyebab adannya porositas pada penuangan paduan aluminium ialah gas hidrogen. Porositas dihitung melalui pengukuran massa jenis, melalui pengukuran berat spesimen di udara dan di dalam air murni, untuk menghitung besarnya porositas suatu material, menggunakan rumus sebagai berikut:

$p$ ap $=p$ liquid $\times \frac{w s}{w s-w s b}$

di mana:

p ap = massa jenis aktual $\left(\mathrm{gram} / \mathrm{cm}^{3}\right)$

$w s \quad=$ berat di udara (gram)

$w s b \quad=$ berat didalam air (gram)

pliquid $=$ massa jenis cairan $\left(\mathrm{gram} / \mathrm{cm}^{3}\right)$

mencari porositas:

$P \%=\left(1-\frac{p a p}{p t h}\right) \times 100 \%$

di mana:

$\mathrm{P} \%=$ porositas

p ap $\quad=$ massa jenis aktual $\left(\mathrm{gram} / \mathrm{cm}^{3}\right)$

$p$ th $=$ massa jenis teoritis $\left(\mathrm{gram} / \mathrm{cm}^{3}\right)$

Untuk mencari nilai densitas terukur menggunakan rumus 1 dan untuk mencari nilai porositas menggunakan rumus 2 (Prasetya dkk, 2012).

b. Struktur Mikro

Menurut Mu'afax dkk (2013) struktur mikro ialah gambar dari sekumpulan fasa-fasa yang diamati dengan teknik metalografi. Metalografi ialah pengujian spesimen menggunakan mikroskop dengan pembesaran beberapa ratus kali, ini bertujuan untuk memperoleh gambaran dan untuk mengetahui sifat logam.

c. Kekerasan vicker

Pengujian kekerasan Vickers menggunakan mata penumbuk yang berbentuk piramida intan bujur sangkar.
Angka kekerasan piramida intan (DPH) atau angka kekerasan Vickers (VHN atau $\mathrm{Hv}$ ), diartikan sebagai beban dibagi luas permukaan lekukan. Luas ini dihitung dari pengukuran mikroskop panjang diagonal jejak. VHN ditentukan dengan persamaan sebagai berikut :

$\mathrm{VHN}=1,8544 . \mathrm{P} / \mathrm{d}^{2}$

di mana:

$\mathrm{P}=$ beban yang bekerja pada penetrator intan $(\mathrm{kg})$

$\mathrm{d}=$ panjang rata-rata diagonal bekas penekan (mm)

Pada hasil pengujian spesimen, lekukan yang benar dari bekas penumbuk piramida intan yang berbentuk bujur sangkar. Waktu penekanan yang diperlukan selama 5 detik, dengan beban $1-100 \mathrm{~kg}$.

\section{METODE PENELITIAN}

Pada penelitian yang dilakukan inimenggunakan metode eskperimen (pengujian labiraturium) paduan $\mathrm{Al}$ (kampas rem dan panci) dilebur didalam tungku kursibel kemudian dituang kedalam cetakan sesuai temperatur tuang yang telah divariasikan, dengan waktu tunggu didalam cetakan styrofoam selama 20 menit. Hasil coran dikeluarkan dan didinginkan dengan temperatur ruang, lalu dilakukan pemotongan untuk dibuat spesimen uji dan selanjurnya dilakukan uji porositas, uji kekerasan, dan pengamatan struktur mikro.

Variabel penelitian terbagi menjadi tiga yaitu variabel bebas: temperatur tuang dan jenis material, variabel terikat: uji porositas, uji kekerasan dan struktur mikro, variabel kontrol: jenis pasir cetakan, pola styrofoam waktu tunggu dalam cetakan, pendinginan. 
Adapun diagram alir penelitian ini dapat dilihat pada Gambar 2.

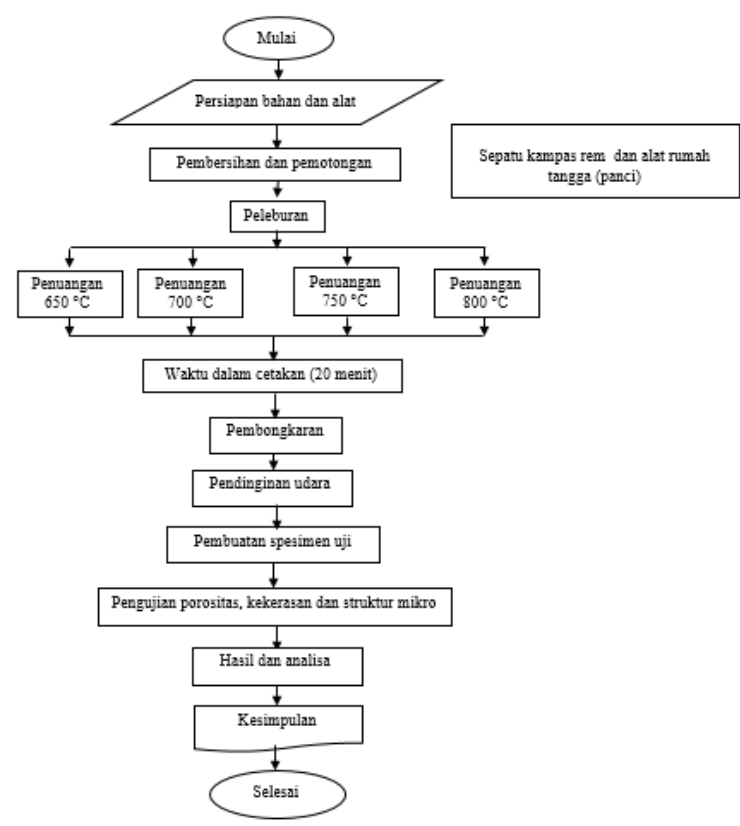

Gambar 2 diagram alir penenlitian

\section{PEMBAHASAN}

\section{Kampas Rem}

a. Struktur Mikro

Hasil dari pengamatan dapat dilihat sebagai berikut:

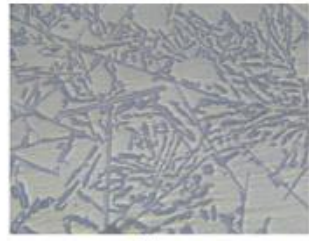

A1

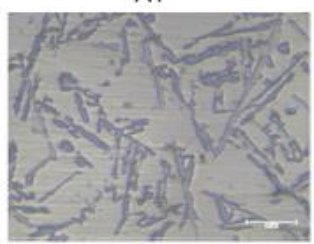

A3

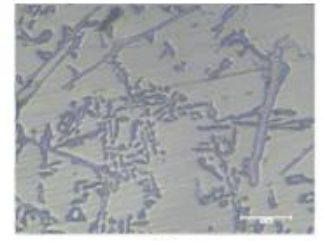

A2

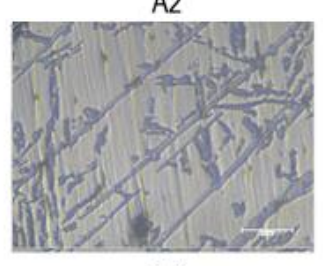

A4
Gambar 3. Spesimen kampas rem
Berdasarkan hasil pengamatan pada foto struktur mikro diketahui bahwa paduan Al memiliki karakteristik yang berbeda-beda pada jenis material sepatu kampas rem terkandung $\mathrm{Si}$ menurut Hermawan dkk (2013). Pada Gambar 3 material jenis sepatu kampas rem rata-rata memiliki struktur $\mathrm{Si}$ berbentuk seperti jarum yang memanjang, hal ini menunjukkan bahwa spesimen kode (A) Bentuk silikon terlihat memanjang diantara matrik aluminium dimana struktur yang memanjang seperti jarumjarum yang halus ini akan menghasilkan kekerasan yang relatif lebih kuat.

\section{b. Porositas}

Pengujian porositas dilakukan untuk mengetahui tingkat porositas yang dialami matrial coran ulang diagram hubungan temperatur tuang terhadap porositas dapat dilihat sebagai berikut:

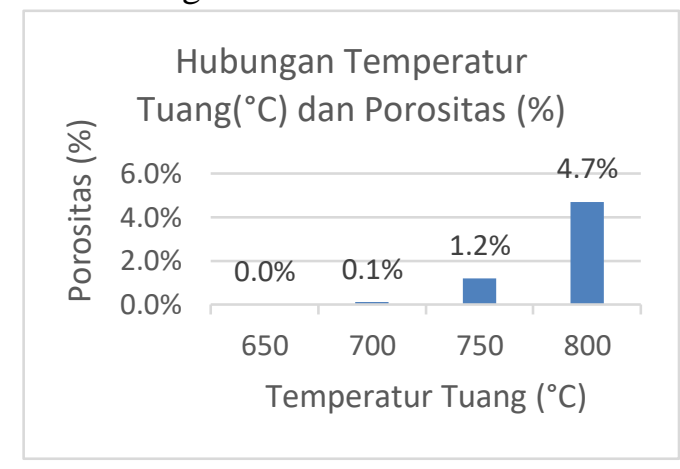

Gambar 4. Hubungan Temperatur Tuang dan Porositas

Dari Gambar 4 terlihat hasil penelitian porositas dari spesimen sepatu kampas rem temperatur tuang $650^{\circ} \mathrm{C}$ hampir mendekati $0 \%$, pada temperatur tuang $700^{\circ} \mathrm{C}$ ada peningkatan porositas sekitar $0.1 \%$, pada temperatur tuang $750^{\circ} \mathrm{C}$ porositas meningkat menjadi $1.2 \%$ kemudian pada temperatur $800^{\circ} \mathrm{C}$ porositas mengalami peningkatan yang tinggi yaitu $4.7 \%$. 
c. Kekerasan

Pengujian kekerasan dilakukan untuk mengatahui tingkat kekerasan yang dimiliki oleh material hasil coran dengan variasi temperatur tuang dan didapat data sebagai berikut:

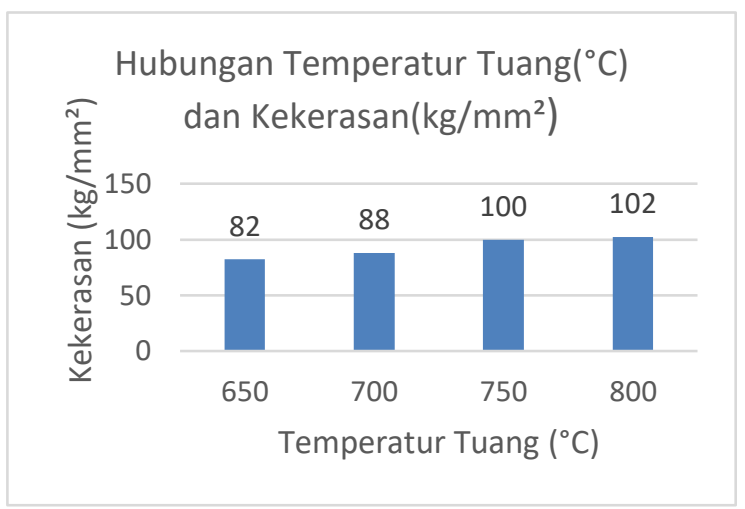

Gambar 5. Hubungan Temperatur Tuang dan kekerasan

Hasil pengujian kekerasan didapatkan tingkat kekerasan pada temperatur tuang $650^{\circ} \mathrm{C}$ didapatkan nilai kekerasan $82 \mathrm{~kg} / \mathrm{mm}^{2}$ lalu pada temperatur tuang $700^{\circ} \mathrm{C}$ naik mencapai $88 \mathrm{~kg} / \mathrm{mm}^{2}$ dan pada temperatur tuang $750^{\circ} \mathrm{C}$ kekerasan yang didapat naik menjadi 100 $\mathrm{kg} / \mathrm{mm}^{2}$ kemudian naik lagi pada temperatur tuang $800^{\circ} \mathrm{C}$ dengan tingkat kekerasan $102 \mathrm{~kg} / \mathrm{mm}^{2}$, dari Gambar 4 terlihat kenaikan temperatur tuang juga diikuti oleh kenaikan tingkat kekerasan sehingga dapat ditarik kesimpulan yaitu semakin tinggi temperatur tuang maka nilai kekerasan juga semakin meningkat.

d. Hasil Analisa

Dari Gambar 4 dan 5 dapat dilihat pada material sepatu kampas rem ketika temperatur tuang $650^{\circ} \mathrm{C}$ mempunyai tingkat kekersan $82 \mathrm{~kg} / \mathrm{mm}^{2}$ dengan porositas hampir mendekati $0 \%$ karena $\mathrm{Al}$ belum dalam temperatur menguap lihat Gambar 7 A1 terlihat dentrite yang banyak, ketika temperatur tuang $700^{\circ} \mathrm{C}$ mempunyai tingkat keketasan yaitu 88 $\mathrm{kg} / \mathrm{mm}^{2}$ dengan porositas $0.1 \%$ terlihat dari Gambar 3 bagian A2 dentrite mulai berkurang dan struktur mulai merata. Pada temperatur tuang $750^{\circ} \mathrm{C}$ kekerasan meningkat menjadi $100 \mathrm{~kg} / \mathrm{mm}^{2}$ dengan porositas $1.2 \%$.

Pada temperatur tuang $800^{\circ} \mathrm{C}$ kekerasan terus naik menjadi $102 \mathrm{~kg} / \mathrm{mm}^{2}$ namun porositas juga naik menjadi $4.9 \%$. Ini seperti penelitian shin dan lee (2004) mengatakan, peningkatan temperatur tuang maka nilai porositas semakin tinggi. Salah satu yang penyebab terjadinya porositas ialah adanya gas hydrogen yang terjebak pada saat proses pembekuan, dimulai dari bagian logam yang bersentuhan dengan cetakan dimana inti kristas mulai tumbuh dan bulit-butir itu memanjang, artinya semakin lama logam mengalami pembekuan dalam cetakan maka porositas semakin tinggi (Raharjo dkk, 2011).

Hasil terbaik pada $750^{\circ} \mathrm{C}$ dengan tingkat kekerasan $100 \mathrm{~kg} / \mathrm{mm}^{2}$ dan nilai porositas hanya $1.2 \%$ pada jenis material ini cenderung getas karena menurut Hermawan,dkk (2013) material kampas rem menggandung $\mathrm{Si}$, yang menyebabkan sifat material menjadi keras. Dalam penelitian ini terlihat semakin temperatur tuang naik tingkat kekerasan juga naik, di ikuti juga porositas yang naik, tingkat kekerasan yang meningkat ini disebabkan paduan Si yang semakin tinggi teperatur tuang maka kekuatan mengikatnya juga semakin mengikat.

\section{Material Panci}

a. Material Panci

Hasil pengamatan pada material panci dapat di lihat pada Gambar 6 . 


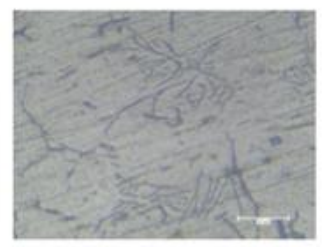

B1

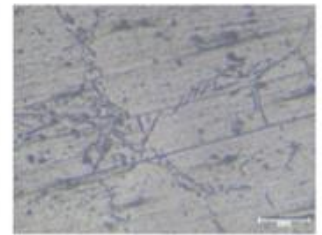

B3

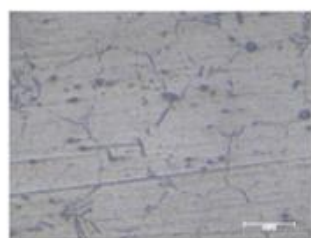

B2

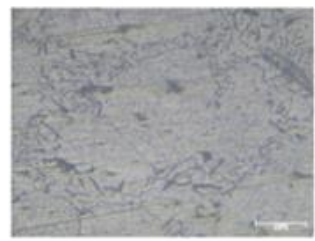

B4
Gambar 6. Spesimen material panci

Pada jenis material panci terlihat susunan strukrur mikro yang didominasi oleh Al seperti telihat pada Gambar 6 terlihat kandungan $\mathrm{Zn}$ yang membentuk seperti garis-garis kecil yang tersebar tidak teratur tapi merata. Dengan adanya perbedaan karakteristik hasil pengecoran $\mathrm{Al}$ paduan rongsok dikarenakan temperatur tuang yang berbeda-beda.

b. Porositas

Dari hasil pengujian porositas jenis material panci dapat dilihat sebagai berikut:

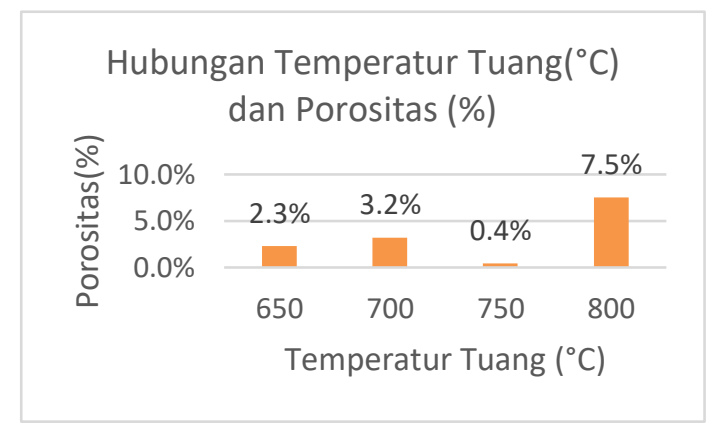

Gambar 7. Hubungan Temperatur Tuang Dan Porositas

Pada temperatur tuang $650^{\circ} \mathrm{C}$ tingkat porositasnya $2.3 \%$ lalu pada temperatur $700^{\circ} \mathrm{C}$ tingkat porositas meningkat menjadi $3.2 \%$, pada temperatur tuang $750^{\circ} \mathrm{C}$ tingkat porositas menurun pesat menjadi $0.4 \%$ kemudian pada temperatur tuang $800^{\circ} \mathrm{C}$ meningkat menjadi $7.5 \%$.

c. Kekerasan

Hasil pengujian kekerasan dapat dilihat sebagai berikut:

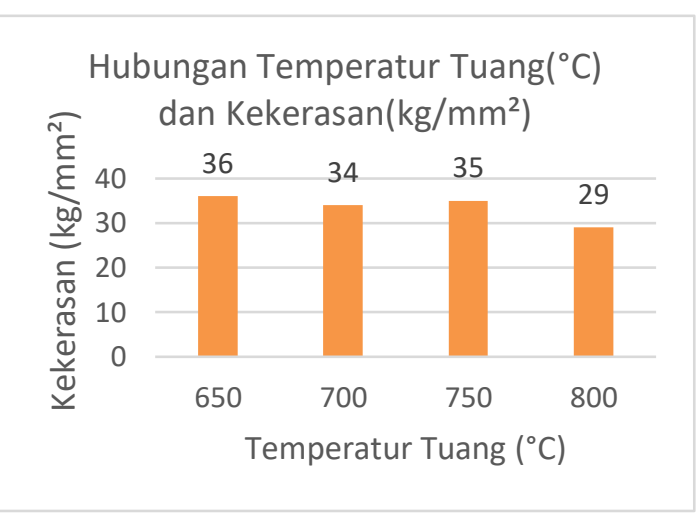

Gambar 8 Hasil Uji Porositas Pada Panci

Gambar 8 menunjukan hubungan temperatur tuang dan tingkat kekerasan hasil dari pengujian kekerasan material panci didapatkan tingkat kekerasan pada temperatur tuang $650^{\circ} \mathrm{C}$ adalah $36 \mathrm{~kg} / \mathrm{mm}^{2}$ kemudian pada temperatur tuang $700^{\circ} \mathrm{C}$ kekerasan menurun menjadi $34 \mathrm{~kg} / \mathrm{mm}^{2}$ kemudian pada pada temperatur tuang $750^{\circ} \mathrm{C}$ tinggkat kekerasan naik menjadi 35 $\mathrm{kg} / \mathrm{mm}^{2}$ kemudian pada temperatur tuang $800^{\circ} \mathrm{C}$ kembali mengalami penurunan kekerasan menjadi $29 \mathrm{~kg} / \mathrm{mm}^{2}$. Dari hasil menunjukan dari kenaikan temperatur $650^{\circ} \mathrm{C}$ ke $700^{\circ} \mathrm{C}$ mengalami menurunan tingkat kekerasan kemudian $700^{\circ} \mathrm{C}$ ke $750^{\circ} \mathrm{C}$ mengalami kenaikan kekerasan lalu dari $750^{\circ} \mathrm{C}$ ke $800^{\circ} \mathrm{C}$ kembali mengalami penurunan kekerasan.

\section{d. Hasil Analisa}

Dari Gambar 7 dan 8 hasil pengujian pada material panci terlihat pada temperatur tuang $650^{\circ} \mathrm{C}$ nilai kekerasan yang didapat $36 \mathrm{~kg} / \mathrm{mm}^{2}$ dan tingkat porositas $2.3 \%$, pada temperatur tuang $700^{\circ} \mathrm{C}$ nilai kekerasan yang didapatkan menurun sampai $34 \mathrm{~kg} / \mathrm{mm}^{2}$ dan tingkat porositas naik menjadi $3.2 \%$, 
pada temperatur tuang $750^{\circ} \mathrm{C}$ nilai kekerasan meningkat sampai $35 \mathrm{~kg} / \mathrm{mm}^{2}$ dan tingkat porositas menutun menjadi $0.4 \%$ dan kemudian pada temperatur tuang $800^{\circ} \mathrm{C}$ kekerasan kembali menurun menjadi $29 \mathrm{~kg} / \mathrm{mm}^{2}$ dan tingkat porositas meningkat sampai $7.5 \%$ lebih tinggi dari sebelumnya. Dan biasanya setelah temperatur optimum tercapai maka tren kekerasan akan cenderung menurun dikarenakan terbentuknya porositas yang meningkat. Data tersebut dapat terlihat nilai kekerasan tertinggi terdapat pada temperatur tuang $750^{\circ} \mathrm{C}$ dengan tingkat porositas $0.4 \%$. sumber yang utama pada porositas adalah hidrogen yang mempunyai daya larut yang tinggi didalam aluminium cair menurut Puga Et $\mathrm{Al}(2009)$.

Berdasarkan pengujian kekerasan dan porositas pada material panci dapat ditarik kesimpulan jika semakin tinggi porositas maka nilai kekerasan akan berkurang ini terllihat pada hasil uji spesimen B3 dengan nilai porositas terkecil yaitu $0.4 \%$ dengan kekerasan tertinggi $35 \mathrm{~kg} / \mathrm{mm}^{2}$, hal ini juga terjadi pada penelitian yang dilakukan Kusharjana, dkk (2012) menyimpulkan bahwa semakin tinggi nilai persentase cacat porositas pada produk cor aluminium cetakan pasir, maka semakin rendah nilai kekerasannya. Perbedaan karakteristik ini menunjukan bahwa temperatur tuang berpengaruh pada sifat mekanik material coran aluminium.

\section{KESIMPULAN}

Dari penelitian ini dapat ditarik kesimpulan sebagai berikut:

1. Temperatur tuang berpengeruh terhadap porositas suatu coran ini terlihat dari hasil penelitian pada material sepatu kampas rem pada temperatur tuang $650^{\circ} \mathrm{C}$ porositas hampir mendekati $0 \%$. Pada $700^{\circ} \mathrm{C}$, $0.1 \%$, pada $750^{\circ} \mathrm{C} 1.2 \%$, pada $800^{\circ} \mathrm{C} 4.7 \%$. kemudian dari jenis material panci menghasilkan pada temperatur tuang $650^{\circ} \mathrm{C}, 2.3 \%$. Pada $700^{\circ} \mathrm{C}, 3.2 \%$, pada $750^{\circ} \mathrm{C}$ $0.4 \%$, pada $800^{\circ} \mathrm{C} 7.5 \%$.

2. Temperatur tuang berpengaruh terhadap kekerasan telihat dari hasil penelitian pada material sepatu kampas rem semakin tinggi teperatur tuang maka tingkat kekerasan juga semakin tinggi, kemudian pada meterial panci tingkat kekerasan menurun ketika temperatur tuang di naikan dari $650^{\circ} \mathrm{C}$ ke $700^{\circ} \mathrm{C}$, lalu pada temperatur tuang $750^{\circ}$ kekerasan sudah mencapai tingkat yang optimal, kemudian turun kembali ditemperatur tuang $800^{\circ} \mathrm{C}$.

3. Pada foto struktur mikro pada masing-masing temperatur tuang dan jenis material menghasilkan struktur yang berbeda-beda ini membuktikan temperatur tuang berpengaruh terhadap hasil struktur mikro mengecoran aluminium. 


\section{DAFTAR PUSTAKA}

Hermawan dkk. 2013, "Analisa Pengaruh Variasi Temperatur Tuang Pada Pengecoran Squeeze Terhadap Struktur Mikro Dan Kekerasan Produk Sepatu Kampas Rem Dengan Bahan Aluminium (Al) Silikon (Si) Daur Ulang”, Teknik Mesin Ft Universitas Wahid Hasyim. Semarang.

Puga, H., et al. 2009. New Trends in Aluminium Degassing-A Comparative Study. Fourth International Conference on Advances and Trends in Engineering Materials and their Applications.

Kusharjanta bambang, wahyu purworaharjo, joko santoso, 2012, "pengaruh bentuk penampang runner terhadap cacat porositas dan nilai kekerasan produk cor aluminium cetakan pasir". Mekanika, Universitas Sebelas Maret, Surakarta.

Raharjo dkk, 2011,"Analisis Pengaruh Pengecoran Ulang Terhadap Sifat Mekanik Paduan Alumunium ADC 12", jurnal teknik mesin fakultas teknik universitas muhammadiyah semarang ISNB. 978-602-99334-06.

Surdia,T. dan Chijiwa, K..2000. Teknik Pengecoran Logam, Cetakan Ke-8, PT. Pradnya Paramita, Jakarta. 